\title{
Analisis Hambatan-Hambatan Komunikasi Mahasiswa-Pembimbing Pada Masa Pandemi Covid-19
}

\section{Analysing Communication Barriers Students-Supervisors in The Covid-19 Pandemic}

\author{
Aulia Rahmawati \\ Universitas Pembangunan Nasional "Veteran” Jawa Timur \\ Email : aulia_rahmawati.ilkom@upnjatim.ac.id
}

\begin{abstract}
The need for better relationship between students-supervisor intensifies especially during the final years. A good communication and better social interaction between students and supervisors will assure the research process and thesis writing executed effectively. However, the pandemic of Covid-19 has conjured several barriers. This paper explored the way in which barriers emerged during the mentoring process of final year students and their supervisors amidst the condition of Covid-19 pandemic. It doing so by generating interviews as well as focus-group-discussions with 24 final-year students. This paper concludes that at least five communication barriers are identified during the research process in April-May 2020. They are semantic, individual, interpersonal, physical-media and technological barriers. It is reveaeld that such barriers are becoming more prevalent and intensified because of the pandemic, especially technological barriers. Digital divide exists even within the major cities in Indonesia and thus need a viable solution from the University to overcome students-supervisors problems.
\end{abstract}

Keywords: students, supervisor, communication, barriers, Covid-19

\begin{abstract}
ABSTRAK
Kebutuhan akan adanya hubungan yang baik dan resiprokal biasanya semakin meningkat ketika mahasiswa menginjak tingkat (semester) akhir di Universitas. Komunikasi dan hubungan interpersonal yang baik antara mahasiswa dan pembimbing akan memastikan proses pengerjaan riset dan penulisan skripsi berjalan dengan baik dan lancar. Namun, pandemi Covid-19 yang membuat hampir seluruh universitas menerapkan kebijakan "work from home" sejak bulan Maret 2020 membuat dinamika mahasiswa-pembimbing menjadi terganggu. Tulisan ini mengurai hambatan dalam proses komunikasi (communication barriers) antara mahasiswa tingkat akhir dengan dosen pembimbingnya. Melalui wawancara mendalam dan FGD dengan 24 mahasiswa tingkat akhir, tulisan ini menyimpulkan setidaknya ada lima hambatan dalam proses berkomunikasi di masa pandemi.
\end{abstract}


Hambatan teknologi merupakan hambatan terbesar bagi mahasiswa-dosen karena kesenjangan digital masih menjadi masalah, bahkan di kota-kota besar di Indonesia. Hambatan ini memutuhkan perhatian khusus dari pihak Universitas agar masalah dosen-pembimbing bisa terselesaikan.

Kata-kata Kunci: mahasiswa, dosen pembimbing, komunikasi, hambatan, Covid-19

\section{PENDAHULUAN}

Mahasiswa tingkat akhir atau di semester terakhir membutuhkan interaksi yang tinggi dengan supervisor (pembimbing skripsi / tugas akhir) nya. Biasanya dalam masa-masa inilah proses komunikasi dilakukan secara intens antara mahasiswa dan pembimbing yang bisa berlangsung lebih dari satu semester. Selayaknya bimbingan dilakukan secara langsung tatap muka dengan berkesinambungan mulai mahasiswa tersebut mengajukan judul / topik dan diakhiri dengan proses penulisan revisi setelah ujian skripsi dilangsungkan. Bisa dibilang, mahasiswa dan pembimbing adalah partner kerja dan membutuhkan hubungan mutualisme resiprokal agar pengerjaan riset dan penulisan laporan (skripsi) bisa berjalan dengan baik. Namun, sejak Maret 2020 berbagai Universitas di Indonesia meniadakan sama sekali tatap muka di kampus baik untuk proses belajarmengajar termasuk proses pembimbingan skripsi.

Proses pembimbingan skripsi yang selama ini terjadi secara langsung (direct) dan menitikberatkan pada face-to-face communication tiba-tiba harus beralih online dengan perantaraan berbagai teknologi komunikasi. Perubahan secara tibatiba dalam semalam ini memunculkan berbagai masalah baru bagi mahasiswa dan dosen pembimbing.
Pandemi memunculkan masalahmasalah baru, terutama menyangkut interaksi mahasiswa-dosen pembimbing dalam kaitannya dengan hambatan proses komunikasi (communication barriers) yang terjadi selama masa pandemi Covid -19. Sehingga, tulisan ini ditujukan untuk mengeksplorasi hal-hal yang bisa diidentifikasikan sebagai hambatan komunikasi (communication barriers) antara mahasiswa dan dosen pembimbing selama masa pandemi.

Interaksi antara dosen pembimbing mahasiswa sejatinya adalah mentoring relationship (Bash, 2009),(ManciniCross et al., 2009). Hal ini bisa didefinisikan sebagai bentuk partnership antara seseorang yang berpengalaman dengan seseorang yang kurang berpengalaman untuk meraih tujuannya (Mulen 2005; Caproni 2012 dalam (DeVito, 2013). Hubungan mentoring yang baik dipersyaratkan oleh beberapa hal menurut (DeVito, 2013) yaitu mutualisme dan open sharing terhadap pekerjaan yang dilaksanakan serta mensyaratkan adanya dukungan (supportive) dan saling percaya (trusting).

Berbagai literatur juga menjelaskan beberapa skill atau keahlian yang harus dimiliki oleh mahasiswa tingkat akhir salah satunya adalah self-efficacy atau bisa dimaknai seberapa jauh mahasiswa bisa mengerjakan segala sesuatu yang menjadi tanggungjawabnya (Lange \& Baillie, 2008). 
Penelitian lain terhadap mahasiswa tingkat akhir juga dilakukan oleh (Akgun \& Ciarrochi, 2003) yang mengidentifikasi "kemampuan untuk mengolah stres dan tuntutan akademik" sebagai salah satu skill yang harus dimiliki mahasiswa tingkat akhir. Riset lainnya dari (Karpouza \& Emvalotis, 2019) juga menandaskan bahwa walau secara hirarki dosen pembimbing memiliki posisi yang lebih tinggi dalam universitas, hubungan mahasiswa - pembimbing harus resiprokal dan memiliki rasa tanggungjawab yang sama.

Communication barriers bisa dipahami sebagai hambatan komunikasi, yang dalam hal ini berhubungan dengan interaksi antara dosen-mahasiswa di saat pandemi Covid -19. Karena jumlah literatur dan penelitian sejenis belum ada, maka penelitian ini akan menggunakan model communication barriers yang ditawarkan oleh UGC net, sebuah lembaga konsultan pendidikan berbasis di India yang juga menyelenggarakan ujian nasional. Sebuah penelitian yang dirilis oleh UGC net, (Barriers et al., 2020) mengidentifikasi penghalang komunikasi, antara lain adalah sebagai berikut

1. Semantic barriers, yaitu yang berhubungan dengan pemahaman pesan antara komunikan dan komunikator.

2. Organizational barriers, yaitu yang berhubungan dengan posisi, jabatan antara komunikan dan komunikator.

3. Interpersonal barriers, yang berhubungan dengan pembawaan, sikap dan nilainilai masing-masing partisipan dalam proses komunikasi tersebut.
4. Individual barriers, berhubungan dengan kondisi psiko-sosial partisipan masing-masing.

5. Cross-cultural barriers, yang berhubungan kultur atau budaya, cara hidup yang berbeda antara masing-masing partisipan.

6. Physical and media barriers, yang berhubungan dengan jarak antara partisipan, dan juga media atau teknologi komunikasi yang dipilih.

7. Technological barriers, yang berhubungan dengan tingkat penguasaan teknologi yang dimiliki oleh masing-masing partisipan.

Ketujuh hambatan komunikasi ini akan diujicobakan dalam ruang lingkup komunikasi mahasiswa pembimbing yang terjadi selama masa pandemi. Bab selanjutnya akan mengulas masalah metode penelitian dengan lebih detil.

\section{METODE PENELITIAN}

Riset secara online sudah merupakan hal yang wajar dalam dekade terakhir karena data-data dan teknologi online memungkinkan peneliti bisa bekerja secara mandiri, tanpa membutuhkan kehadiran manusia maupun tim riset yang besar (Fielding et al., 2008).

Namun dalam masa pandemi, melakukan riset secara online adalah satu-satunya pilihan metode yang bisa dilakukan karena mobilitas manusia harus dibatasi sesuai keputusan pemerintah. Metode riset yang dipilih adalah online FGD (focus group discussions) dan online interviews. Partisipan riset adalah mahasiswa tingkat akhir (yang sedang 
mengerjakan skripsi) di beberapa semester yang berbeda, yaitu semester 8, 10 hingga semester 12 . Empat belas mahasiswa berhasil diwawancarai secara daring dalam dua kali FGD, sedangkan sisanya diwawancarai tertulis secara terpisah melalui saluran Whatsapp. Interview terjadi secara synchronous (umpan balik terjadi di waktu yang sama), maupun asynchronous (peneliti mengirimkan set pertanyaan dan partisipan membalas di waktu yang tidak bersamaan). Sehingga riset ini secara total berhasil mengumpulkan 24 mahasiswa tingkat akhir yang sedang mengerjakan riset dan menulis skripsi. Wawancara dan FGD dilakukan sepanjang bulan April-Mei 2020, dalam fase awal saat pandemi Covid-19.

Hasil wawancara yang telah ditranskrip akan dianalisis untuk bisa mengidentifikasi sekaligus mengeksplorasi mana diantara ketujuh hambatan komunikasi yang telkah diuraikan dalam sub-bab pendahuluan diatas yang bisa ditemukan dalam data penelitian ini. Patut diingat bahwa karena riset telah dilakukan di fase awal pandemi (bulan April-mei 2020) maka bisa jadi beberapa hambatan tidak akan sama atau relevan ketika dibandingkan pada paruh terakhir tahun 2020.

Research consent (kesediaan riset) dibacakan diawal sebelum wawancara (baik FGD maupun individual). FGD rata-rata membutuhkan waktu satu jam yang kemudian di-rekam seijin partisipan dan diputuskan akan menggunakan pseudonym ketika akan dipublikasikan. Partisipan yang direkrut adalah mahasiswa Ilmu Komunikasi UPN Veteran Jawa Timur yang sedang dalam proses menuntaskan riset dan menulis laporannya dalam bentuk skripsi. Beberapa mahasiswa yang direkrut sebagai partisipan juga berhasil lulus ketika tulisan ini diterbitkan.

Riset secara online walaupun menawarkan berbagai kemudahan namun juga memiliki keterbatasan. Salah satunya adalah tidak bisa leluasa mengamati bahasa tubuh atau gesture partisipan. Sehingga analisis data sepenuhnya bersumber pada hasil wawancara 24 partisipan semata tanpa menambahkan observasi terhadap perilaku partisipan selama wawancara. Beberapa mahasiswa juga merupakan bimbingan langsung dari penulis sehingga diperkirakan ada keenganan untuk menceritakan kondisi yang sesungguhnya. Pun begitu, secara umum data-data yang dihasilkan cukup akurat menggambarkan kondisi yang sesungguhnya dari interaksi mahasiswa dan dosen pembimbing selama pandemi.

Beberapa hambatan lainnya yang terkait teknologi juga ditemukan selama masa pengumpulan data. Terkadang ada kendala jaringan yang terputus atau terhambat ketika wawancara berlangsung. Sekilas, secara reflektif perjalanan riset ini mewakili apa yang menjadi hambatan(barriers) dalam proses komunikasi dan interaksi antara mahasiswa-pembimbing dalam masa pandemi. Uraian lebih lanjut disajikan dalam sub-bab berikutnya.

\section{HASIL DAN PEMBAHASAN}

Hasil wawancara (individual maupun FGD) selanjutnya dibuat dalam bentuk transkrip yang mudah dipahami. Transkrip ini kemudian dibaca berkali-kali hingga bisa disimpulkan 
hambatan komunikasi apa saja yang dimunculkan selama wawancara. Halangan-halangan yang diidentifikasi baik secara eksplisit maupun implisit dari transkrip wawancara kemudian dikelompokkan dalam tujuh jenis commmunication barriers, seperti yang telah diuraikan dalam sub-bab pendahuluan diatass.

Dibawah ini akan diuraikan lebih lanjut satu persatu. Patut digarisbawahi bahwa terkadang antara hambatan komunikasi yang satu dan yang lainnya saling terkait sehingga antara satu hambatandan yang lainnya terkadang sulit dibedakan.

\section{Semantic Barriers}

Hambatanjenis ini bisa ditemukan dalam medium interaksi antara mahasiswa-pembimbing yang tibatiba berubah. Interaksi yang tadinya berjalan secara langsung face-to-face tiba-tiba dipaksa untuk berpindah dalam medium lain, dengan perantaraan teknologi komunikasi.

Beberapa masalah dalam interaksi terjadi karena masalah semantik, yaitu menyangkut pemahaman pesan antara pembimbing dan mahasiswa. Beberapa mahasiswa menyatakan bahwa kerap kesalahpahaman terjadi antara dosen dan mahasiswa karena perubahan medium komunikasi dari offline menuju online. Sebelumnya Whatsapp kerap digunakan oleh mahasiswa sekedar untuk membuat janji dengan pembimbing, namun setelah pandemi dengan segala keterbatasan teknologi maka Whatsapp menjadi pilihan untuk berkonsultasi. Sifat dan karakteristik teknologi instant messaging seperti Whatsapp yang efisien dan cepat serta sesingkat-singkatnya membuat 'bahasa WA' menjadi sulit untuk dipahami kedua belah pihak. Dilain pihak, teknologi video conference juga memiliki banyak kendala antara lain karena memakan quota internet yang tidak sedikit. Hal ini membuat pilihan video conference jarang dipilih oleh pembimbing dan mahasiswa.

Hambatan semantik terjadi dalam momen-momen percakapan yang terjadi lewat Whatsapp. Antara lain adalah instruksi pembimbing yang sulit dipahami karema terlalu singkat maupun persoalan etika dalam mengirimkan pesan yang kerap dikeluhkan oleh para pembimbing, misalnya mahasiwa mengirim pesan diluar jam-jam kerja, pesan terlalu informal dan lain sebagainya.

Beberapa program studi dan jurusan sampai memutuskan untuk menerbitkan 'aturan' bahasa Whatsapp yang sopan dan baik sebagai panduan mahasiswa untuk berkomunikasi dengan dosennya. Seperti yang dikatakan oleh mahasiswa berikut:

"Terkadang kita juga beda persepsi ya. Bagi aku rasanya sudah sopan, tapi bagi dosen tertentu rasanya masih nggak sopan. Jadinya ya sulit." (AR, semester 10)

"Apalagi bahasa WA kan memang terbatas ya. Beda banget lah sama bercakapcakap secara langsung. Saya sendiri harus membaca berkali-kali untuk memastikan kalau bahasanya sudah sopan. Takut menyinggung. Jam-jam mengirim WA juga saya pikirkan bener. Hubungan saya sama pembimbing sih deket sebenarnya, cuman ya harus 
diingat kalau mereka itu bagaimanapun dosen kita, lebih tua dan yang diurusin juga bukan skripsi kita doang. Jadinya ya memang kita harus usaha lebih banyak sih untuk berkomunikasi" (ET, semester 8)

\section{Interpersonal Barriers}

Hambatan interpersonal terjadi karena ada perbedaan budaya, norma, kepercayaan dan nilai-nilai yang dianut oleh pembimbing dan mahasiswa. Sebelum pandemi pun, hambatan interpersonal kerap terjadi, karena pembimbing merasa sikap yang ditunjukkan oleh mahasiswa tidak memiliki rasa hormat, misalnya. Perbedaan ini terutama semakin dipertajam oleh pandemi, karena interaksi secara langsung tidak diperbolehkan. Sangat berkaitan dengan hambatan semantik, hambatan ini terjadi karena adanya perbedaan persepsi antara pembimbing dan mahasiswa tentang apa yang disebut sebagai perilaku yang sopan dalam menggunakan media komunikasis. Seperti yang diungkapkan oleh beberapa mahasiswa:

"Terkadang suka ada pembimbing yang salah paham ya. Dipikir kita mengejar-ngejar mereka lewat WA. Padahal ya, karena pesan kita dicuekin sama mereka" (EDS, Semester 8)

"Ada sih memang beberapa mahasiswa yang nggak sopan. Maksudnya bahasanya kayak orang nagih. Kirim WA nggak tahu waktu, disamain kayak temannya. Tetep namanya etika harus dijaga ya." (HMG, Semester 8)

Mayoritas mahasiswa yang menjadi partisipan juga mengeluhkan interaksi yang sangat kurang dengan adanya pandemi. Terlebih jika pembimbing tidak menawarkan opsi lain, hanya melalui Whatsapp misalnya. Mengerjakan sebuah riset ditengahtengah pandemi membutuhkan dukungan yang memadai dari para pembimbing, dan bagi sebagian mahasiswa dukungan ini tidak didapatkan sebagaimana mestinya sehingga mereka merasa 'seorang diri'.

\section{Individual Barriers}

Perasaan sendirian, kesepian juga kerap ditemukan selama masa-masa wawancara. Beberapa mahasiswa menyiratkan permasalahan yang serupa, bahwa perasaan terisolasi menjadi begitu mengemuka pada saat pandemi. Berbeda dengan mahasiswa yang masih mengikuti perkuliahan secara daring, mahasiswa tingkat akhir diharapkan bekerja mandiri untuk riset dan penulisan skripsinya. Tidak adanya kesempatan untuk bertemu dengan 'teman-teman seperjuangan' yang sama-sama mengerjakan skripsi adalah sebuah hambatan psikologis bagi para mahasiswa ini.

Beberapa penelitian serupa juga menyoroti masalah kesepian dan depresi pada beberapa mahasiswa di perguruan tinggi. Beberapa peneliti (Hartt, 2020) mengungkapkan bahwa tingkat depresi mahasiswa diseluruh dunia meningkat dengan signifikan dan merupakan gabungan dari perasaan kesepian, depresi hingga kecemasan (anxiety) yang berlebihan. 
Beberapa mahasiswa mengungkapkan hal yang senada sebagai berikut:

"kangen sama teman-teman yang sama-sama sedang mengerjakan skripsi. Biasanya kami saling menguatkan." (NM, semester 10)

"Memang di rumah saja, tapi anggota keluarga yang banyak kok malah bikin nggak bisa konsen ya. Selalu rame. Memang rame, tapi kok rasanya makin kesepian." (CP, semester 8)

"Walaupun saya tahu kita ngerjakan topik sendirisendiri tapi kalau seringsering ngumpul rasanya ada temannya. Nah, kan nggak mungkin selama pandemi. Bisanya juga Whatsapp-an aja. Nggak cukup rasanya." (EH, semester 10)

Insitusi pendidikan di Indonesia kerapkali tidak memiliki fasilitas konseling dan dukungan yang memadai untuk mahasiswa. Sehingga, hambatan psikologis lebih sering ditangani oleh pembimbing akademik masing-masing (yang tidak memiliki kemampuan dan pengetahuan memadai tentang psikologis mahasiswa). Dalam masa pandemi, hambatan ini semakin membesar.

\section{Physical and Media Barriers}

Hambatan fisik dan media berkaitan dengan jarak antar partisipan dan media yang dipilih untuk berinteraksi dan berkomunikasi. Beberapa mahasiswa (dan pembimbing) yang diwawancarai sempat mengeluhkan hal ini. Terutama bagi mereka yang memutuskan untuk pulang ke daerah masing-masing menjauhi kota Surabaya. Pilihan untuk bekerja dari rumah membawa tantangan, terutama ketika daerah asal mahasiswa ataupun pembimbing belum mendapatkan akses internet. Ataupun jika sudah memiliki akses internet, jaringan yang didapat tidak cukup kuat untuk terhubung sepanjang waktu atau tidak memungkinkan untuk melakukan video conference.

Pilihan media yang diambil juga menjadi hambatan bagi beberapa pembimbing dan mahasiswa. Tidak semua pembimbing memiliki kemampuan teknis dan penguasaan teknologi. Membutuhkan niat dan usaha bagi pembimbing untuk bisa menggunakan teknologi video conference, misalnya. Beberapa pembimbing enggan atau tidak bersedia menggunakan video conference sama sekali, kecuali untuk urusan mengajar. Sehingga, aktivitas pembimbingan skripsi sangat terhambat. Komunikasi lewat Whatsapp dirasa tidak memadai untuk konsultasi tentang skripsi. Konflik antara mahasiswa dan pembimbing pun biasanya terjadi disini. Seperti yang diungkapkan oleh salah satu mahasiswa,

“ Pembimbing saya nggak mau melakukan konsultasi lewat Zoom. Di Whatsapp juga dijawab singkat-singkat. Bisa dibilang saya nggak dibimbing sama sekali. Padahal skripsi kan tidak bisa begitu. Kami butuh dukungan yang baik juga." (EZ, semester 8)

"Pembimbing saya masalahnya agak gaptek orangnya. Tapi kasihan juga 
kalau memaksa harus menggunakan Zoom. Kan nggak nyaman juga kalau memaksa. Jadi ya saya yang menyesuaikan diri dengan beliaunya. Yang enak bagaimana, pokoknya bimbingan tetap berjalan dengan baik." (EH, semester 8)

Relasi kuasa mahasiswa dan dosen pembimbing memang masih menempatkan pembimbing memiliki kuasa yang lebih besar dibanding bimbingannya (Davis et al., 2020). Seperti dinyatakan diatas, hubungan mentoring yang baik hanya bisa dicapai bila ada partnership antara mahasiswa dan pembimbing yang seimbang (Dawson et al., 2019). Kondisi pandemi ini membuat jurang relasi kuasa mahasiswa dan pembimbing semakin lebar. Tidak ada cara lain untuk menemukan solusinya selain melalui lembaga audit internal Universitas untuk bisa melakukan koreksi dan peringatan atas temuantemuan ini.

\section{Technological Barriers}

Hambatan ini sangat erat kaitannya dengan physical and media barriers yang telah diuraikan diatas. Kemampuan dosen dan mahasiswa terhadap penguasaan teknologi berbeda-beda, begitupun akses setiap orang terhadap teknologi tersebut.

Dalam index digital divide, Indonesia menempati urutan bawah di Asia Tenggara, dibawah Filipina, Vietnam dan Thailand (Iswara, 2020). Laporan tersebut menjelaskan bahwa internet dan teknologi komunikasi masih merupakan privilege bagi sebagian masyarakat. Bantuan pemerintah untuk Covid-19 banyak terkendala masalah ketimpangan teknologi digital antara yang urban dan rural, antara kelas menengah dan kelas bawah. Hambatan teknologilah yang diidentifikasi sebagai hambatan tersbesar antara mahasiswapembimbing disaat pandemi.

Dalam kaitannya dengan penelitian ini, di tingkat perguruan tinggi-pun masalah ketimpangan teknologi begitu terasa. Sebuah komunitas akademik yang seharusnya diharapkan 'melek' dan 'terampil' teknologi juga dihadapkan pada keterbatasanketerbatasan infrastruktur teknologi. Hal ini harus disadari oleh kedua belah pihak. Mahasiswa dan pembimbing sebaiknya sama-sama menyadari bahwa ada problem teknologi sehingga bisa menemukan formula interaksi yang unik, yang bisa jadi berbeda dengan mentorship yang lainnya. Model interaksi yang berhasil bagi mahasiswa-pembimbing satu barangkali tidak bisa diterapkan bagi mahasiswa-pembimbing lainnya. Syaratnya adalah harus ada itikad baik dari masing-masing partisipan untuk memecahkan hambatan ini. Itikad itu harus resiprokal, tidak bisa berat sebelah. Bagi pihak universitas, harus dipikirkan pendidikan dengan blended learning dan multi-platform untuk mengatasi keterbatasan-keterbatasan teknologi yang solusinya tidak bisa dicapai dalam semalam.

Proses komunikasi yang multiplatform yang tidak seratus persen bertumpu pada akses internet akan membuat proses pembimbingan bisa berjalan dengan efektif dan mahasiswa mendapatkan dukungan yang semestinya. 


\section{KESIMPULAN}

Tulisan ini mengeksplorasi hambatan komunikasi yang terjadi diantara mahasiswa tingkat akhir dan dosen pembimbingnya, dalam rangka pengerjaan riset dan penulisan skripsi. Kondisi pandemi telah membuka hambatan yang diidentifikasi sebagai hambatan semantik, hambatan interpersonal, hambatan individual, hambatan fisik dan media serta hambatan teknologi. Yang tidak tampak atau minim dalam penelitian ini adalah hambatan lintas budaya (cross-cultural) dan hambatan organisasi. Diantara berbagai hambatan yang diidentifikasi, hambatan teknologilah yang diidentifikasi sebagai hambatan tersbesar antara mahasiswapembimbing disaat pandemi.

Beberapa hal yang ditawarkan bagi pengelola atau pimpinan Universitas adalah menawarkan beberapa solusi untuk memperkecil hambatan tersebut. Salah satunya adalah dengan menawarkan bimbingan konseling bagi mahasiswa yang menghadapi hambatan individual yang bersifat psiko-sosial. Beberapa instutusi pendidikan tinggi di Indonesia yang memiliki fakultas Psikologi sudah merintis layanan konseling ini.

Terkait hambatan yang terkait dengan teknologi, pihak pengelola Universitas juga bisa memperkecil halangan ini. Salah satunya dengan mengaktifkan fasilitas e-learning yang bisa diakses dalam kondisi offline atau tanpa jaringan. Sehingga, dimanapun mahasiswa berada, ia memiliki akses yang sama terhadap materi perkuliahan. Namun, kondisi mahsiswa tingkat akhir yang sudah tidak membutuhkan kuliah bisa disiasati dengan bantuan quota internet bagi mahasiswa sekaligus bagi dosen pembimbing. Pembimbing harus mengadopsi blended-learning yang menawarkan fleksibilitas serta multi-platform untuk mengakomodasi kesulitan-kesulitan yang dihadapi mahasiswa.

Secara reflektif, kondisi yang luar biasa membutuhkan solusi yang 'diluar kebiasaan' juga. Pandemi ini memaksa institusi perguruan tinggi untuk menempuh cara-cara kreatif untuk tetap bisa melaksanakan hak dan kewajibannya. Cara-cara kreatif harus ditempuh pula supaya proses mentoring tetap berjalan, apapun rintangannya. Kekakuan hubungan pembimbing dan mahasiswa yang biasanya cenderung formal selayaknya menjadi lebih dinamis untuk memecahkan penghalanghambatan yang ada.

\section{DAFTAR PUSTAKA}

Akgun, S., \& Ciarrochi, J. (2003). Learned resourcefulness moderates the relationship between academic stress and academic performance. Educational Psychology, 23(3), 287-294.

Barriers, C., On, N., To, B., \& Communication, E. (2020). Communication Barriers : Notes On Barriers To Effective Barriers to Effective Communication Types of Communication Barriers. 1-13. https://ugcnetpaper1.com/com munication-barriers/

Bash, L. (2009). Engaging with crosscultural communication barriers in globalized higher education: the case of research-degree students. Intercultural Education, 20(5), 475-483.

Davis, C., King, O. A., Clemans, A., 
Coles, J., Crampton, P. E. S., Jacobs, N., McKeown, T., Morphet, J., Seear, K., \& Rees, C. E. (2020). Student dignity during work-integrated learning: a qualitative study exploring student and supervisors' perspectives. Advances in Health Sciences Education, 25(1), 149172.

Dawson, P., Henderson, M., Mahoney, P., Phillips, M., Ryan, T., Boud, D., \& Molloy, E. (2019). What makes for effective feedback: Staff and student perspectives. Assessment \& Evaluation in Higher Education, 44(1), 25-36.

DeVito, J. A. (2013). The interpersonal communication book 13th ed. New Jersey: Pearson Education, Inc.

Fielding, N. G., Lee, R. M., \& Blank, G. (2008). The SAGE handbook of online research methods. Sage.

Hartt, M. (2020). COVID-19: a lonely pandemic. Cities \& Health, 1-3.

Iswara, M. A. (2020). Mega-Drop

Moment : Blue Quartz

Disconnected : Digital divide may jeopardize human rights. 1-9.

https://www.thejakartapost.co $\mathrm{m} /$ news/2020/05/18/disconne cted-digital-divide-mayjeopardize-human-rights.html

Karpouza, E., \& Emvalotis, A.

(2019). Exploring the teacherstudent relationship in

graduate education: a

constructivist grounded theory. Teaching in Higher Education, 24(2), 121-140.

Lange, K., \& Baillie, C. (2008).

Exploring graduate student

learning in applied science and student-supervisor relationships: views of supervisors and their students. Engineering
Education, 3(1), 30-43.

Mancini-Cross, C., Backman, K. F., \& Baldwin, E. D. (2009). The effect of the language barrier on intercultural communication: A case study of educational travel in Italy. Journal of Teaching in Travel \& Tourism, 9(1-2), 104-123. 